\title{
ANALYSIS OF PLATELET INDICES AND ITS PREDICTIVE VALUE IN DIAGNOSIS OF THROMBOCYTOPENIA
}

\author{
K. Swarajya Kumari ${ }^{1}$, Azam Begum Heena ${ }^{2}$, M. Lavanya ${ }^{3}$
}

${ }^{1}$ Associate Professor, Department of Pathology, Osmania Medical College/Osmania General Hospital, Koti, Hyderabad, Telangana, India.

2Senior Resident, Department of Pathology, Osmania Medical College/Osmania General Hospital, Koti, Hyderabad, Telangana, India. ${ }_{3}^{3}$ Assistant Professor, Department of Pathology, Osmania Medical College/Osmania General Hospital, Koti, Hyderabad, Telangana, India.

\section{BACKGROUND}

ABSTRACT

Thrombocytopenia can be due to decreased production of platelets in bone marrow or due to increased destruction. Aetiology of thrombocytopenia can be evaluated by determination of platelet indices, whether it is hypoproductive or hyperdestructive type. Platelet indices (MPV, PDW, P-LCR, Platelet-Crit) are simple, cost-effective, non-invasive and reliable tool to differentiate types of thrombocytopenias.

The main objective of the study was to evaluate the variation and relationship of platelet indices in hypoproductive and hyperdestructive thrombocytopenia cases.

\section{MATERIALS AND METHODS}

Automated Haematology Analyzer Sysmex XN-1000i is used to assess platelet indices. 70 cases of thrombocytopenia were included in our study. Inclusion and exclusion criteria applied.

\section{RESULTS}

This study includes 70 patients of thrombocytopenia over a period of 2 months, who were classified into hypoproductive (32 cases) and hyperdestructive (38 cases). The mean platelet count in hypoproduction group was (56.5 \pm 18.5$) \times 103 / \mathrm{mm}$ and mean platelet indices were MPV $=(10.6 \pm 0.12) \mathrm{fL}, \mathrm{PDW}=(10.6 \pm 0.13) \mathrm{fL}, \mathrm{P}-\mathrm{LCR}=(28.93 \pm 1.3) \%$ and Platelet-Crit $(0.05 \pm 0.02)$. The mean platelet count of hyperdestructive group $(41.3 \pm 15.3) \times 103 / \mathrm{mm}$, mean platelet indices MPV= $(11.4 \pm 0.89) \mathrm{fL}, \mathrm{PDW}=(12.2 \pm 2.16) \mathrm{fL}, \mathrm{P}-$ $\mathrm{LCR}=(36.1 \pm 5.3) \%$ and Platelet-Crit $(0.05 \pm 0.01)$.

\section{CONCLUSION}

The combined interpretation of MPV, PDW and P-LCR by automated cell counters can be very useful parameters in differentiating thrombocytopenias due to various aetiologies. Platelet indices showed inverse relationship with platelet count as they are increased in hyperdestructive type and shows linear relationship in hypoproliferative type. Platelet-Crit is a less sensitive parameter to differentiate these thrombocytopenias.

\section{KEY WORDS}

Hyperdestructive Thrombocytopenia, Hypoproductive Thrombocytopenia, Platelet Large Cell Ratio, Mean Platelet Volume (MPV), Platelet Distribution Width (PDW) and Platelet-Crit (PCT).

HOW TO CITE THIS ARTICLE: Kumari KS, Heena AB, Lavanya M. Analysis of platelet indices and its predictive value in diagnosis of thrombocytopenia. J. Evolution Med. Dent. Sci. 2018;7(26):3023-3027, DOI: 10.14260/jemds/2018/679

\section{BACKGROUND}

Thrombocytopenia is an important clinical finding in hospitalised patients. During evaluation it is essential to identify the aetiology of thrombocytopenia, whether it is due to hypoproduction or hyperdestruction, as this will have effect over the proper management of the patients. ${ }^{1}$

Bone marrow aspiration is the gold standard method for assessing the cause of thrombocytopenia, but this procedure is invasive, time consuming and carries an overt risk of bleeding diathesis in critical cases. ${ }^{2}$ Of late with the use of automated

'Financial or Other Competing Interest': None.

Submission 15-05-2018, Peer Review 09-06-2018,

Acceptance 14-06-2018, Published 25-06-2018.

Corresponding Author:

Dr. Azam Begum Heena,

H. No. 20-5-366,

$1^{\text {st }}$ Floor, Qazipura, Hyderabad,

Telangana, India.

E-mail: azambegumheena@gmail.com

DOI: $10.14260 /$ jemds $/ 2018 / 679$

\section{(c) $($ ) $\ominus$}

cell counters various platelet indices such as mean platelet volume, platelet distribution width and platelet-crit and P-LCR can be measured with a simple complete blood count and may provide some valuable data $^{3}$ in estimating aetiology of thrombocytopenia.

\section{Aim}

To evaluate variation in platelet indices to differentiate hypoproductive type from hyperdestructive thrombocytopenias.

\section{MATERIALS AND METHODS}

This is a cross-sectional study done for a period of 2 months in a tertiary care centre, comprises of total 70 cases. Diagnosis was established based on clinician diagnosis. Some are already diagnosed relapsed cases and for some cases bone marrow aspiration was done to establish the diagnosis.

Platelet count and various platelet indices like Mean Platelet Volume (MPV), Platelet Distribution Width (PDW), Platelet-Crit (PCT) and platelet large cell ratio of the thrombocytopenic patients were done in Automated 
Haematology Analyzer Sysmex XN-1000i. Correlation with routine peripheral smear findings of particular cases was done. Significant clinical details and available investigations including serological results of the patients were included. The gender was not taken into interpretation, as the range of platelet indices are almost same for both gender.

\section{Inclusion Criteria}

All patients with a platelet count of less than $1,50,000 / \mathrm{mm} 3$, confirmed by peripheral blood smear and bone marrow aspiration.

\section{Exclusion Criteria}

Patients on antiplatelet drugs and other medications causing thrombocytopenia were excluded.

\section{Automated Haematology Analyser XN 1000i Works on Three Basic Principles ${ }^{4}$ as Follows:}

- Fluorescence Flow Cytometry using a semiconductor laser $(639 \mathrm{~nm})$ : evaluates physiological and chemical characteristics of cells as the blood sample is aspirated and measured, diluted to the specified ratio and stained and a semiconductor laser beam is emitted. The forward scattered light is received by the photodiode and the lateral scattered light and lateral fluorescent light are received by the photomultiplier tube. This light is converted into electrical pulses.

Forward scattered light provides information on blood cell size and lateral scattered light provides information on the cell interior (nucleus) and by measuring the intensity of the fluorescence emitted you can obtain information of RNA/ DNA content of the cell.

- Impedance-based sensor for cell detection and analysis using Hydrodynamic Focussing for RBC and PLT analysis: diluted sample is injected into RBC PLT detector which passes through the middle of aperture via hydrodynamic focussing and causes an electrical resistance recorded as impedance pulse. Cell size is proportional to pulse height. With the help of this detection, principle RBC and platelet histograms are generated.

- $\quad$ Sodium lauryl sulfate Haemoglobin Method- cyanide-free Haemoglobin analysis.

Platelets are differentiated from non-platelet fragments and red blood cells with the help of (log-normal) distribution curve generated from the initial platelet histogram.

Optical or impedance method generates platelet distribution curve from which platelet indices like Mean Platelet Volume (MPV), Platelet Distribution Width (PDW) and the platelet large cell ratio can be derived (Table 1).(5-7)

Mean platelet volume is the measurement of average size of the platelet reported in femtolitre (fL) and is available on most haematology analysers. $(5,6,8)$

Platelet distribution width is the measurement of variation in size of platelets. Either calculated from platelet distribution width at $20 \%$ frequency level or as the standard deviation of platelet volume divided by MPV $\times 100.6$ Platelet indices which are derived from platelet histogram are highly specific with different analysers having different reference ranges. ${ }^{6}$

Platelet large cell ratio (P-LCR) measures the percentage of platelets larger than $12 \mathrm{fL} .(5,6)$
Platelet indices that are calculated from platelet distribution curve are influenced by the factors that affect the platelet count like interference from cells or cell fragments, insufficiency in detecting platelet clumps and giant platelets.

Erroneous result of platelet indices like overestimation of MPV, increased value of PDW and increased platelet large cell ratio (P-LCR) occur when red blood cells are misclassified as platelets.

It is difficult to have platelet distribution curve in patients with severe thrombocytopenia and hence calculation of platelet indices is not possible in such cases. ${ }^{6}$

\section{Blood Sample Collection}

Blood samples obtained from vein puncture are collected in EDTA anti-coagulant vacutainer in $1.5 \mathrm{mg} / 1 \mathrm{~mL}$ ratio of whole blood. Thoroughly mix the sample immediately after collecting into the vacutainer to prevent clot formation, then the sample is registered into Sysmex XN 1000i automated haematology analyser.

A total of 70 samples were selected for the study, gender was not taken into account as the range of platelet indices are almost the same for both gender.

The specific parameters included in the study were PLT count, MPV, PDW, P-LCR and PLT-crit.

Anticoagulant used for platelet count can affect the calculation of platelet indices. For example K2 or K3 Ethylenediaminetetra Acetic Acid (EDTA) leads to an increase in MPV from $7.9 \%$ within 30 mins to $13.4 \%$ over $24 \mathrm{~h}$ when it is measured by impedance and decreases MPV by $10 \%$ when calculated by an optical method.6,8) Other variables for example PDW and the fraction of large cells ${ }^{8}$ apart from MPV are also affected by this time delay. Processing the sample as soon as possible, preferably within 120 mins is recommended to avoid erroneous results. ${ }^{9}$ EDTA can also lead to agglutination of platelets, which results in a falsely low platelet count (pseudo-thrombocytopenia). Therefore, each laboratory should possess methods to detect this. ${ }^{7}$

\section{Samples Quality Control Checking System}

In this system, platelet histogram errors flag was carefully inspected to eliminate unreliable erroneous flagged results. The various defining criteria are as follows:

MPV is average size of the platelets in Blood. MPV $=$ (mean $\pm \mathrm{SD})(\mathrm{fL}), \mathrm{MPV}=(9.7 \pm 1.48) \mathrm{fL}$.

Variation in platelet size comprising of both small platelets and giant/ mega platelets is an indication of hyperproduction of platelets in bone marrow is calculated as PDW (Mean \pm SD) $\%$, PDW= $(14.46 \pm 1.68) \%$.

Platelet-Crit is a measure of total platelet mass. Normal range of PCT is $0.1-0.31 \%$.

P-LCR increases in conditions with lead to increase peripheral destruction of platelets than those with decrease production. Hence, P-LCR has inverse relation to platelet count and it is directly related to PDW and MPV.P-LCR $=($ mean $\pm \mathrm{SD})$ (\%); P-LCR= $(33.40 \pm 2.96) \%$.

\section{Data Collection and Analysis}

Details of the patients like clinical history, presenting complaints, treatment details and previous haemogram reports if any- above data are collected from medical records.

Quantitative data analysis of the platelet indices was done. Mean and standard deviations were calculated. Measured 
platelet parameters between the two groups of thrombocytopenic patients were statistically tested by unpaired ' $\mathrm{t}$ ' test to obtain the P-value. Statistically significant result is considered, when P-value obtained is less than 0.05 .

\section{RESULTS}

Our study was done on 70 of thrombocytopenic patients who were classified into hypoproductive and hyperdestructive group. In the hypoproductive we had 32 cases and in the hyperdestruction there were 38 cases. Measured platelet parameters were statistically tested using unpaired test. The distribution of cases in each subgroup and comparison of the distribution with similar studies were shown in Table 2.
The mean platelet count in the hypoproduction group is (56.5 \pm 18.5$) \times 10^{3} / \mathrm{mm}$ and in the hyperdestruction group is $(41.3 \pm 15.3) \times 10^{3} / \mathrm{mm}$, having a P-value of 0.0004 . Mean of platelet indices like mean MPV in the hypoproduction group is $10.6 \pm 0.12$ and in the hyperdestruction group is $11.4 \pm 0.89$ resulting in a significant $\mathrm{P}$-value of $<0.0001$. Mean PDW in the hypoproduction group is $10.6 \pm 0.13$ and in the hyperdestruction group is $12.2 \pm 2.16$ having a $\mathrm{P}$-value of $<0.0001$. Mean P-LCR in the hypoproduction group is $28.93 \pm$ 1.3 and in the hyperdestruction group is $36.1 \pm 5.3$ with a Pvalue of $<0.0001$. The mean PCT in the hypoproduction group is $0.05 \pm 0.02$ and in the hyperdestruction group is $0.05 \pm 0.01$ having a P-value of 1 . Mean values of different platelet indices and P-value in hyperdestruction thrombocytopenia and hypoproduction thrombocytopenia were shown in Table 3.

\begin{tabular}{|c|c|c|c|c|}
\hline Parameter & Coulter Principle & Benefits & Drawbacks & Applications \\
\hline Platelet count & $\begin{array}{c}\text { Calculated usually by } \\
\text { impedance method in } \\
\text { automated flow } \\
\text { cytometric analysis }\end{array}$ & $\begin{array}{l}\text { Quick, simple and often } \\
\text { requires less amount of } \\
\text { blood }\end{array}$ & $\begin{array}{c}\text { Less accurate and has high \% CV } \\
\text { in severe thrombocytopenia. This } \\
\text { test is highly reliable on } \\
\text { procedure used for calculation } \\
\text { and often fails to detect platelet } \\
\text { clumps and giant platelets }\end{array}$ & $\begin{array}{l}\text { Indicative of thrombocytopenia, } \\
\text { but in general has no relationship } \\
\text { with risk of bleeding in } \\
\text { thrombocytopenic patients }(10-12)\end{array}$ \\
\hline $\begin{array}{l}\text { MPV- Mean } \\
\text { platelet } \\
\text { volume }\end{array}$ & $\begin{array}{c}\text { Derived value obtained } \\
\text { from the platelet } \\
\text { distribution curve }\end{array}$ & $\begin{array}{l}\text { Quick, simple and often } \\
\text { requires less amount of } \\
\text { blood, commonly used }\end{array}$ & $\begin{array}{c}\text { Value varies with platelet } \\
\text { distribution curve, as it is derived } \\
\text { from it }\end{array}$ & $\begin{array}{c}\text { Indicative of bone marrow failure } \\
\text { as a cause of low platelet } \\
\text { count.(13-18) Decrease MPV value } \\
\text { along with platelet count of }<20 \\
\times 10^{9} / \mathrm{L}^{19} \text { result in bleeding } \\
\text { manifestation }\end{array}$ \\
\hline \begin{tabular}{|c|}
$\begin{array}{c}\text { PDW- Platelet } \\
\text { distribution } \\
\text { width }\end{array}$ \\
\end{tabular} & \begin{tabular}{|c|} 
Derived value obtained \\
from the platelet \\
distribution curve
\end{tabular} & $\begin{array}{c}\begin{array}{c}\text { Quick, simple and often } \\
\text { requires less amount of } \\
\text { blood }\end{array} \\
\end{array}$ & $\begin{array}{c}\begin{array}{c}\text { Value varies with platelet } \\
\text { distribution curve, as it is derived } \\
\text { from it }\end{array} \\
\end{array}$ & $\begin{array}{r}\text { No data available } \\
\text { bleeding r } \\
\text { thrombocytope }\end{array}$ \\
\hline \begin{tabular}{|c|} 
P-LCR- Platelet \\
large cells \\
ratio \\
\end{tabular} & $\begin{array}{c}\text { Derived value obtained } \\
\text { from the platelet } \\
\text { distribution curve }\end{array}$ & $\begin{array}{c}\text { Quick, simple and often } \\
\text { requires less amount of } \\
\text { blood }\end{array}$ & $\begin{array}{c}\text { Value varies with platelet } \\
\text { distribution curve, as it is derived } \\
\text { from it }\end{array}$ & $\begin{array}{l}\text { No data available to correlate } \\
\text { bleeding risk in } \\
\text { thrombocytopenic patients }\end{array}$ \\
\hline
\end{tabular}

\begin{tabular}{|c|c|c|c|}
\hline Aetiologies & $\begin{array}{c}\text { Total Number of Cases in } \\
\text { Present Study (\%) }\end{array}$ & $\begin{array}{c}\text { Katti et al }{ }^{20} \\
\text { Total Cases (\%) }\end{array}$ & \begin{tabular}{|c} 
Shaheena et al and Vimal et al \\
Total Cases $(\%)$
\end{tabular} \\
\hline \multicolumn{4}{|c|}{ Hypoproduction } \\
\hline Severe anaemia & $05(7.1 \%)$ & & \\
\hline Megaloblastic anaemia & $15(21.4 \%)$ & $08(8 \%)$ & $11(9.2 \%)$ \\
\hline Leukaemia & $06(8.5 \%)$ & $06(6 \%)$ & $2(1.7 \%)$ \\
\hline CKD & $06(8.5 \%)$ & & \\
\hline Others & & & $13(10.8 \%)$ \\
\hline \multicolumn{4}{|c|}{ Hyperdestructive } \\
\hline ITP & $11(15.7 \%)$ & $4(4 \%)$ & $3(2.5 \%)$ \\
\hline Dengue & $08(11.4 \%)$ & $29(29 \%)$ & $26(21.7 \%)$ \\
\hline Malaria & $05(7.1 \%)$ & $24(24 \%)$ & $8(6.7 \%)$ \\
\hline Chronic liver disease & $05(7.1 \%)$ & $4(4 \%)$ & $20(16.7 \%)$ \\
\hline Sepsis & $01(1.4 \%)$ & $4(4 \%)$ & $6(5 \%)$ \\
\hline Others & $08(11.4 \%)$ & $21(21 \%)$ & $31(25.8 \%)$ \\
\hline Total & 70 & 100 & 120 \\
\hline
\end{tabular}

\begin{tabular}{|c|c|c|c|}
\hline Platelet Indices & Hypoproduction & Hyperdestruction & P Value \\
\hline Platelet count $\left(\right.$ mean \pm SD) $\left(\times 10^{3} / \mathrm{mm} 3\right)$ & $(56.5 \pm 18.5)$ & $(41.3 \pm 15.3)$ & 0.0004 \\
\hline MPV (mean \pm SD) $(\mathrm{fL})$ & $10.6 \pm 0.12$ & $11.4 \pm 0.89$ & $<0.0001$. \\
\hline PDW $($ mean \pm SD) $(\mathrm{fL})$ & $10.6 \pm 0.13$ & $12.2 \pm 2.16$ & $<0.0001$ \\
\hline P-LCR (mean \pm SD) $\%$ & $28.93 \pm 1.3$ & $36.1 \pm 5.3$ & $<0.0001$ \\
\hline PCT $($ mean \pm SD) $\%$ & $0.05 \pm 0.02$ & $0.05 \pm 0.01$ & 1 \\
\hline
\end{tabular}




\section{DISCUSSION}

Thrombocytopenia is defined as platelet count below $150,000 / \mathrm{mm}^{3}$. It is a frequent complication in patients admitted in an emergency care, ${ }^{21}$ hence its early detection is important for proper management of the patients. Hence, the methods to distinguish between the types of thrombocytopenia like hypoproductive due to reduced production and hyperdestructive thrombocytopenia is necessary. Automated Haematology Analyzer used for the measurement of platelet indices has many advantages over manual estimation as it is very simple, quick and inexpensive test which also eliminates the observer bias.22,23 Further in manual method, a delay between collection of blood and smear preparation may change the platelet morphology and also artifactual increase in platelet diameter can occur because of increased adhesiveness with flattening of the platelets on the smears. 24

Though these parameters have been available in past from the routinely used blood cell counters in the laboratory, their exact role in application to clinical diagnosis has still not been fully established. ${ }^{25}$ In our study thrombocytopenia is divided into hypoproductive and hyperdestructive type based on the aetiology.

In our study, PLT indices (MPV, PDW, P-LCR, PCT) measured by Sysmex XN 1000i very well correlated with other published studies.

Shaheena Parveen et al and Mourouguessine Vimal et al found a significant low $(10.17 \pm 1.3)$ mean MPV in the hypoproduction group than in the hyperdestruction group $(12.3 \pm 0.9)$, which is comparable to our study.

Study done by Numbenjapon et al conclude that MPV was significantly high in hyperdestruction thrombocytopenia group than hypoproductive thrombocytopenia. In hyperdestructive thrombocytopenia, bone marrow compensates actively for the platelet loss and start releasing young larger platelets ("left shift"), which tend to decrease in size during its 7 - 10 days lifespan. ${ }^{26}$

Ntaios et al found an increased MPV and PDW in Immune Thrombocytopenic Purpura (ITP).

Kaito et al similarly found a substantial increase in MPV and PDW in ITP than in aplastic anaemia.

Few studies found a high PDW can also result in hyperdestructive thrombocytopenia, because of the release of heterogeneous population of platelets which vary in their size (Anisocytosis). ${ }^{27,28}$

PCT is a representation of volume percent of platelets and its value is not altered by severity of thrombocytopenia of either hypoproductive or hyperdestructive aetiology. In this study, we did not find any major difference in PCT among the two subgroups.

\section{CONCLUSION}

The mean platelet volume is useful in discriminating the hypoproductive and hyperdestructive thrombocytopenia. Thus, interpretation of platelet indices can help the patients to avoid unnecessary invasive investigations like bone marrow aspiration and unnecessary platelet transfusion. Platelet indices showed inverse relationship with platelet count as they are increased in hyperdestructive type and show linear relationship in hypoproliferative type. Platelet-Crit is less sensitive parameter to differentiate these thrombocytopenias.

\section{REFERENCES}

[1] Parveen S, Vimal M. Role of platelet indices in differentiating hypoproductive and hyperdestructive thrombocytopenia. Annals of Pathology and Laboratory Medicine 2017;4(3):A288-91.

[2] Kaito K, Otsubo H, Usui N, et al. Platelet size deviation width, platelet large cell ratio, and mean platelet volume have sufficient sensitivity and specificity in the diagnosis of immune thrombocytopenia. Br J Haematol 2005;128(5):698-702.

[3] Park Y, Schoene N, Harris W. Mean platelet volume as an indicator of platelet activation: methodological issues. Platelets 2002;13(5-6):301-6.

[4] XN-Series Training Manual Sysmex UK Training Academy, Sysmex UK Ltd Sysmex House Garamonde Drive Milton Keynes Buckinghamshire MK8 8DF, PR000063 Version 2 Unrestricted 2012.

[5] Salignac S, Latger-Cannard V, Schlegel N, et al. Platelet counting. Methods Mol Biol 2013;992:193-205.

[6] Briggs C. Quality counts: new parameters in blood cell counting. Int J Lab Hematol 2009;31(3):277-97.

[7] Zandecki M, Genevieve F, Gerard J, et al. Spurious counts and spurious results on haematology analysers: a review. Part I: platelets. Int J Lab Hematol 2007;29(1):4-20.

[8] Buttarello M, Plebani M. Automated blood cell counts: state of the art. Am J Clin Pathol 2008;130(1):104-16.

[9] Slichter SJ, Kaufman RM, Assmann SF, et al. Dose of prophylactic platelet transfusions and prevention of hemorrhage. N Engl J Med 2010;362(7):600-13.

[10] Friedmann AM, Sengul H, Lehmann H, et al. Do basic laboratory tests or clinical observations predict bleeding in thrombocytopenic oncology patients? A reevaluation of prophylactic platelet transfusions. Transfus Med Rev 2002;16(1):34-45.

[11] Stanworth SJ, Dyer C, Casbard A, et al. Feasibility and usefulness of self-assessment of bleeding in patients with haematological malignancies and the association between platelet count and bleeding. Vox Sang 2006;91(1):63-9.

[12] Bowles KM, Cooke LJ, Richards EM, et al. Platelet size has diagnostic predictive value in patients with thrombocytopenia. Clin Lab Haematol 2005;27(6):3703.

[13] Thon JN, Italiano JE Jr. Does size matter in platelet production? Blood 2012;120(8):1552-61.

[14] Ntaios G, Papadopoulos A, Chatzinikolaou A, et al. Increased values of mean platelet volume and platelet size deviation width may provide a safe positive diagnosis of idiopathic thrombocytopenic purpura. Acta Haematol 2008;119(3):173-7.

[15] Numbenjapon T, Mahapo N, Pornvipavee R, et al. A prospective evaluation of normal mean platelet volume in discriminating hyperdestructive thrombocytopenia from hypoproductive thrombocytopenia. Int J Lab Hematol 2008;30(5):408-14.

[16] Niethammer AG, Forman EN. Use of the platelet histogram maximum in evaluating thrombocytopenia. Am J Hematol 1999;60(1):19-23. 
[17] Ten Berg MJ, Huisman A, van den Bemt PM, et al. Discriminative value of platelet size indices for the identification of the mechanism of chemotherapyinduced thrombocytopenia. Biomarkers 2011;16(1):51-7.

[18] Eldor A, Avitzour M, Or R, et al. Prediction of haemorrhagic diathesis in thrombocytopenia by mean platelet volume. $\mathrm{Br}$ Med J (Clin Res Ed) 1982;285(6339):397-400.

[19] Lance MD, van Oerle R, Henskens YM, et al. Do we need time adjusted mean platelet volume measurements? Lab Hematol 2010;16(3):28-31.

[20] Katti TV, Mhetre SC, Annigeri C. How far are the platelet indices mirror image of mechanism of thrombocytopenia-mystery still remains? Int J Adv Med 2014;1(3):200-5.

[21] Baig MA. Platelet indices -evaluation of their diagnostic role in pediatric thrombocytopenia. Int J Res Med Sci 2015;3(9):2284-9.

[22] Beyan C, Kaptan K, Ifran A. Platelet count, mean platelet volume, platelet distribution width and plateletcrit do not correlate with optical platelet aggregation responses in healthy volunteers. J Thromb Thrombolysis 2006;22(3):161-4.
[23] Borkataky S, Jain R, Gupta R, et al. Role of platelet volume indices in the differential diagnosis of thrombocytopenia: a simple and inexpensive method. Hematology 2009;14(3):182-6.

[24] Nelson RB III, Kehl D. Electronically determined platelet indices in thrombocytopenic patients. Cancer 1981;48:954-6.

[25] Giovanetti TV, do Nascimento AJ, de Paula JP. Platelet indices: laboratory and clinical applications. Rev Bras Hematol Hemoter 2011;33(2):164-5.

[26] Kottke-Marchant K, Corcoran G. The laboratory diagnosis of platelet disorders: an algorithmic approach. Arch Pathol Lab Med 2002;126(2):133-46.

[27] Rajantie J, Javela K, Joutsi-Korhonen L, et al. Chronic thrombocytopenia of childhood: use of non-invasive methods in clinical evaluation. Eur J Haematol 2004;72(4):268-72.

[28] Gardner FH, Bessman JD. Thrombocytopenia due to defective platelet production. Clin Haematol 1983;12(1):23-38. 